\title{
Lingüística en el poema: Una visión borgeana del lenguaje
}

Andrés Gallardo B.

Universidad de Concepción

1. En un trabajo orientador acerca de las corrientes que buscan ampliar el campo de interés de los estudios del lenguaje, Ambrosio Rabanales (1979: 244) propone llamar "literolingüística" a aquella interdisciplina

cuyo objeto de estudio es la relación lenguaje-literatura, basada en el postulado de que la obra literaria es, ante todo, "una forma particular de lenguaje", esto es, una estructura estratificada de signos plurisignificativos.

Sin desconocer la legitimidad del punto de vista que concibe la "literolingüística" como la conjunción de dos enfoques diferentes, parece válido intentar una aproximación unificadora, siempre en el campo interdisciplinario, de una realidad compleja como es la producción literaria. Así, en este trabajo pretendo abordar un texto poético de Jorge Luis Borges como un hecho de lenguaje, o sea, acercarme al poema con interés de lingüista, pero consciente de que se trata, ni más ni menos, de un poema.

2. La poesía es, antes que nada, arte; es, insistamos, arte de lenguaje, o sea, el poema se hace con palabras. Nuestra tradición académica ha tenido dos maneras de acercarse al hecho poético: una es entendiéndolo en el marco de cierta tradición expresiva (lo que llamamos la "historia literaria"), y la otra es tratando de desentrañar, a partir de su constitución textual, su sentido y su funcionamiento, lo que se ha llamado "análisis retórico", o "estructural", o "estilístico", o "poético" propiamente dicho. Esta última aproximación unificadora es la propuesta hace ya cuatro décadas por Roman Jakobson (1960). Mi interés, sin embargo, va por un carril algo diferente. Mi propósito es intentar un análisis de lingüista del texto en cuestión, pero no en el sentido de explicitar su estructura fonética, gramatical o semántica, o su especificidad "poética", sino una 
búsqueda un tanto más sutil y, por cierto, más arriesgada. Basado en el postulado de que el lenguaje es, quizás todavía antes que un sistema de comunicación, un sistema de articulación de la experiencia humana, quiero indagar lo que hay en el poema de acto de conocimiento. Concretamente, existen ciertos poemas cuyo tema es el lenguaje mismo. Considerando que el poema es una manifestación culturalmente privilegiada del lenguaje, es por lo menos razonable plantear que la potencialidad cognitiva de éste se vea exaltada en aquél. Quiero decir que un poema acerca del lenguaje puede ser particularmente relevante para el lingüista, quien halla en el poeta una especie de colega de lucidez y capacidad explicatoria sorprendente. Esto es lo que he llamado "lingüística en el poema", al examinar un poema de Jorge Guillén, titulado precisamente "Los nombres", que, al centrarse en el acto lingüístico básico, como es el proceso de designación, es un verdadero texto de teoría lingüística sin dejar de ser un poema, poniendo así de manifiesto que la poesía puede constituirse sin duda en un potente y delicado método de investigación (Gallardo, 1991).

3. En el presente trabajo, pues, abordo la obra poética, más precisamente un poema, de Jorge Luis Borges como un texto cuyo tema es el lenguaje. Mi interés es mostrar cómo en ese poema late una visión del lenguaje en toda su complejidad de mecanismo de articulación de la experiencia humana, de sistema comunicativo asentado en una tradición cultural específica, generador de redes de interacción y de identidad. No pretendo -no podría hacerlo- ser un académico especialista en la obra de Borges. Soy un mero lingüista que halla en la poesía de Borges un valiosísimo conjunto de intuiciones y observaciones acerca del sentido y funcionamiento del lenguaje en la compleja red de interacciones que es la cultura humana.

Jorge Luis Borges es un poeta de la cultura; más específicamente un poeta de la literatura. Su gran tema son los hechos humanos, señalados o nimios, tocados por la actividad literaria. Su mismo sistema de vivencias personales se articula en poema sólo al insertarse en una tradición expresiva. Tal parece ser el criterio básico de realidad de la literatura borgeana. Así lo expresó muchas veces, como en el notable poema cuyo título es, significativamente, "Un lector" y donde, entre otras cosas, su propia identidad se engasta en su condición lectora:

Que otros se jacten de las páginas que han escrito, a mí me enorgullecen las que he leído.

No habré sido un filólogo, no habré inquirido las declinaciones, los modos, la laboriosa mutación de las letras, 
la de que se endurece en te,

la equivalencia de la ge y de la $k a$.

Pero a lo largo de todos los años he profesado

la pasión del lenguaje.

Mis noches están llenas de Virgilio;

haber salido y haber olvidado el latín

es una posesión, porque el olvido

es una de las formas de la memoria...

(Elogio de la sombra, 1969)

Muchas veces se ha tildado a Borges de ser una especie de escritor etéreo, o sea, ajeno a las circunstancias concretas de su entorno cultural o, peor aun, de ser un intelectual europeizante encerrado en una torre de marfil y traidor a la tradición hispanoamericana. Nada más falso. Borges es un escritor sudamericano, específicamente argentino, que se asoma al mundo desde su condición de tal. En una ya larga tradición latinoamericana universalista que toma forma madura en el joven Rubén Darío de $A z u l . .$. , Borges no reniega ni de su argentinidad -al revés, la siente exacerbada-, ni de la tradición de raigambre hispánica que subyace, por encima de todo, en la lengua. Sarlo (1995: 51) lo ha señalado de modo irredargüible:

Borges dibujó uno de los paradigmas de la literatura argentina: una literatura construida (como la nación misma) en el cruce de la cultura europea con la inflexión rioplatense del castellano en el escenario de un país marginal.

Borges se asoma, así, a la cultura universal, y se apropia de ella, desde la tradición cifrada en lengua castellana. Más de una vez el escritor ha expresado esta visión en su obra ensayística más intelectualizada, a menudo polemizante (Gallardo 1968), pero también, para lo que aquí interesa, en su producción propiamente poética. Así leemos en su exaltación "Al idioma alemán":

Mi destino es la lengua Castellana, El bronce de Francisco de Quevedo, Pero en la lenta noche caminada Me exaltan otras músicas más íntimas.

(El oro de los tigres, 1972)

La vieja literatura castellana, si bien compartida con otras tradiciones cifradas en otras lenguas, es, para Borges, tradición, raíz e identidad. Es una presencia de realidad permanente en toda su producción, sobre todo poética. Es, incluso, una obsesión para este lector vital, que aúna en su proyecto expresivo 
la tradición etnocultural y la tradición literaria, simbolizándolas muchas veces en un nombre también obsesivo, como es el de Miguel de Cervantes o, más propiamente, el de Don Quijote de la Mancha (o quizás Alonso Quijano):

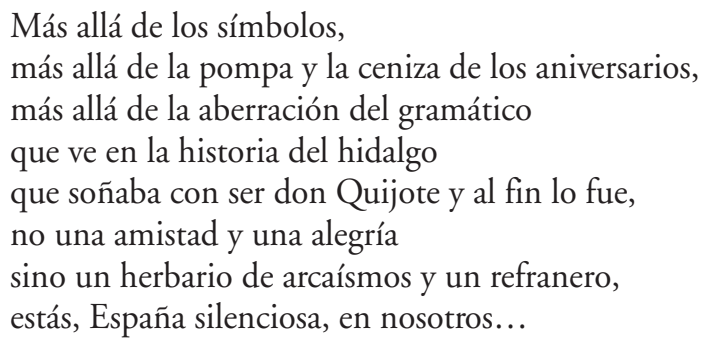

Más allá de los símbolos, más allá de la pompa y la ceniza de los aniversarios, más allá de la aberración del gramático que ve en la historia del hidalgo que soñaba con ser don Quijote y al fin lo fue, no una amistad y una alegría sino un herbario de arcaísmos y un refranero, estás, España silenciosa, en nosotros...

(El otro, el mismo, 1964)

4. Borges ha expresado sus puntos de vista sobre el lenguaje en numerosos ensayos. Para mantener la coherencia del enfoque asumido en este trabajo, aceptemos el pie forzado de considerar sólo los planteamientos e intuiciones contenidos en su producción poética.

Una primera forma de aproximación al lenguaje que hallamos en Borges está, comprensiblemente, emparentada con la vieja filología, que parte de los textos, sobre todo literarios, para alcanzar una comprensión del hecho lingüístico. Más que el conocimiento de lingüistas, los textos borgeanos, tanto ensayísticos como narrativos y aun poéticos, trasuntan lecturas de filósofos antiguos y modernos y de los viejos indoeuropeístas. Los grandes temas de esta vertiente se hacen eco de antiguas disquisiciones sobre la relación del lenguaje con el conocer (aristotélicos versus platónicos) y sobre el lugar del lenguaje en el ámbito de la dimensión semiológica de la cultura (ver Muñoz Millanes, 1977, para una sistematización de este aspecto de la visión borgeana del lenguaje).

Una incisiva visión de esta inquietud entroncada con las antiguas disquisiciones de los filósofos del lenguaje ( $\mathrm{y}$ aun con algunas inquietudes de la semiología) la hallamos encarnada en el conocido soneto a Johannes Brahms:

\footnotetext{
Yo que soy un intruso en los jardines que has prodigado a la plural memoria del porvenir, quise cantar la gloria que hacia el azul erigen tus violines. He desistido ahora, para honrarte no basta esa miseria que la gente suele apodar con vacuidad el arte. Soy un cobarde. Soy un triste. Nada podrá justificar esa osadía
} 
de cantar la magnífica alegría

-fuego y cristal- de tu alma enamorada.

Mi servidumbre es la palabra impura, vástago de un concepto y de un sonido; ni símbolo, ni espejo, ni gemido, tuyo es el río que huye y que perdura.

(La moneda de hierro, 1976)

Como señala Ana María Barrenechea (1977: 606), a cuya lucidez debemos el haber puesto de manifiesto la relevancia de este texto,

la música es una de las metáforas borgeanas de ese anhelo de absoluto. En los primeros ensayos podía soñar con el lenguaje de Dios o de los ángeles, siguiendo a Santo Tomás, noción que en realidad es la negación del concepto de lenguaje y de signo pues propone la comunicación indirecta sin intermediarios. Luego pudo encontrar en la música lo más cercano a esa utopía del lenguaje angélico, liberada de la servidumbre de los signos biplánicos (sonido-sentido).

Ello es sin duda cierto, entre otras cosas porque en el sistema cultural de Borges, como en el de tantos otros artistas, late una ilusión de llegar algún día a una expresión totalizadora y no mediatizada de las grandes intuiciones. Pero lo concreto, y lo fundamental para los propósitos de este trabajo, es la conciencia que manifiesta Borges de la dinámica diferente de dos sistemas de signos. La música es un sistema aparentemente no mediatizado, pues su rasgo definitorio es la asemanticidad de sus construcciones, ya que los sonidos, materia prima de la música (al igual que del lenguaje), no "significan" propiamente tal, sino que la composición musical, como un todo orgánico, se constituye, mediante el sonido, en un sistema de relaciones que nos adentra directamente en el mundo de "significación" (no hay otro modo de decirlo) que le es propio, interno. La obra musical carece de un referente, en el sentido en que lo tiene el lenguaje. Por eso la música se nos aparece como más cercana al ideal absoluto que imaginamos sólo patrimonio angélico o aun divino. El lenguaje, por su parte, si bien conlleva efectivamente una forma de servidumbre, por cuanto la palabra no puede disociar la dimensión material -el sonido- de la dimensión inmaterial -el significado-, se instala, y precisamente por ello, en el centro mismo de lo humano. De ahí se sigue que el lenguaje es, y Borges lo entiende bien, un sistema o construcción muy abstracto pero cimentado en lo concreto, y que ocurre en el espacio y en el tiempo, o sea, puede ser expresión del individuo sólo cuando se inserta en una tradición cultural específica. Por eso, la visión borgeana del lenguaje se elabora a partir de su propia experiencia de la lengua castellana, según ya hemos indicado. 
5. En los poemas más entrañables de Borges centrados en el lenguaje, o mejor dicho en la lengua castellana, hallamos esta clara conciencia de que los seres humanos incorporamos -y luego articulamos y expresamos- las experiencias vitales mediante la lengua y de que esta articulación sólo es posible si se engrana en una tradición cultural. Así se entiende en el poema que motiva el presente trabajo, y a partir del cual trataremos de sistematizar la penetrante y diáfana comprensión borgeana del lenguaje: "La luna" (ver Apéndice).

El tema de "La luna" es el lenguaje en su dimensión cultural, específicamente histórica, como generador de identidad. El poema mismo, y esto es también crucial, se instituye, en su organización textual, en una metáfora del lenguaje. De ahí su doble interés para el lingüista.

El asunto mismo del poema, la luna, ya lo inserta en una larga tradición cultural, específicamente poética, de la literatura. El misterio luminoso de nuestro satélite ha concitado el interés de los poetas desde el origen mismo de la poesía. Borges quiere partir de este tópico como un poeta más, pero desde el comienzo lo centra en el sentido totalizador de su poema: en la luna se cifra la grandeza y la limitación del lenguaje humano. Un poeta primigenio concibe el proyecto "desmesurado" de dar cuenta en su texto de todo lo existente. Cuando parecía haber terminado, se da cuenta de una omisión:

Cuenta la historia que en aquel pasado
tiempo en que sucedieron tantas cosas
reales, imaginarias y dudosas,
un hombre concibió el desmesurado
proyecto de cifrar el universo
en un libro y con ímpetu infinito
erigió el alto y arduo manuscrito
y limó y declamó el último verso.
Gracias iba a rendir a la fortuna
cuando al alzar los ojos vio un bruñido
disco en el aire y comprendió, aturdido,
que se había olvidado de la luna.

Ya hemos visto en el soneto a Brahms cómo Borges concibe la lengua como "servidumbre", esto es, dependencia y limitación, al tener que enmarcarse necesariamente en los márgenes del signo, sonido y sentido. Aquí nuevamente el conocimiento poético ilumina este rasgo del lenguaje, e incorpora un nuevo elemento, una nueva limitación o servidumbre, cual el hecho de que el lenguaje es, sin duda, un modo de apropiarse del mundo, pero esta apropiación tiene un rasgo constitutivo ineludible, y es que es necesariamente articulada, o sea, un sistema compuesto de elementos que llevan en sí su irremediable finitud, 
siendo la totalidad sólo un permanente anhelo imposible de conseguir, aunque no de imaginar:

Siempre se pierde lo esencial. Es una

ley de toda palabra sobre el numen.

No lo sabrá eludir este resumen

de mi largo comercio con la luna.

Hay más. Desde el comienzo también, el poeta intuye algo más acerca de la lógica interna del lenguaje: aunque condenados a la limitación, sólo a través de la lengua podemos ejercer ese comercio que se llama intercambio comunicativo, y esto, además, no ocurre en abstracto, sino en el marco de una tradición. El lenguaje podrá ser innato al ser humano, pero es también heredado; historia y geografía, individual y colectivo. Sus orígenes se pierden en la tradición, que va desde la vaga historia de la humanidad al más inmediato entorno familiar argentino "del pozo y de la higuera", y al mismo tiempo es el modo de incorporar las vivencias personales más íntimas, esas noches de "luna compartida", así como de expresarlas:

No sé dónde la vi por vez primera, si en el cielo anterior a la doctrina del griego, o en la tarde que declina sobre el patio del pozo y de la higuera. Según se sabe, esta mudable vida puede, entre tantas cosas, ser muy bella, y hubo así alguna tarde en que con ella te miramos, oh luna, compartida.

Para Borges la tradición es vital y omnipresente, sobre todo la tradición literaria. Sólo desde esa tradición puede configurar su identidad y expresar su mundo personal. Su intuición poética le permite entender que todo gesto lingüístico, todo uso individual de la lengua, es, para que tenga sentido, una continuidad, un eco de gestos del pasado (De esta convicción emana una importante clave para entender el concepto borgeano de "originalidad"). No se trata aquí de una herencia biológica -por cierto real y presente en el lenguaje-, sino de una continuidad comunicativa. Como ha señalado magistralmente Culvert Watkins (1976: XX),

our ancestors, in a real cultural sense, are our linguistic ancestors... But it must be stressed that linguistic heritage, while it may well tend to correspond with cultural continuity, does not imply genetic or biological descent. 
Luego de revisar la presencia de la luna en la tradición literaria, la continuidad de asombros y hallazgos en la visión de poetas de diversas lenguas, este Borges letrado y literato que se sabe y se siente parte de esa tradición, vuelve nuevamente sobre sí mismo, pues, como hemos dicho, sabe también que la individualidad sólo existe en la comunidad, y explicita su inserción en la tradición comunicativa. Más aún, en la tradición idiomática, más concretamente en la continuidad literaria occidental -su pasado donde se aúnan lo afectivo y lo intelectual- es donde halla la real fuente de su identidad:
Más que las lunas de las noches puedo recordar las del verso: la hechizada dragon moon que da horror a la balada y la luna sangrienta de Quevedo.

Insistamos, de paso, en cómo Borges se inserta en la tradición cultural de occidente en su condición de escritor argentino; para él, desde este punto de vista, Leopoldo Lugones es tan válido y tan presente como Quevedo o Shakespeare o Poe:

Cuando, en Ginebra o Zurich, la fortuna
quiso que yo también fuera poeta,
me impuse, como todos, la secreta
obligación de definir la luna.
Con una suerte de estudiosa pena
agotaba modestas variaciones
bajo el vivo temor de que Lugones
ya hubiera usado el ámbar o la arena.

Detengámonos en un aspecto crucial de este trozo del poema. El joven poeta lunario y argentino, inserto en la tradición occidental, al igual que aquel otro mítico poeta que quiso cifrar, mediante el lenguaje, el universo todo, pretendía "definir" la luna, esto es, dar cuenta de su esencia. Lo lamentable es que tal empresa está condenada de antemano al fracaso, por mucho que se busque el aval de otros grandes poetas. Y una vez más la lucidez del conocimiento poético nos ilumina: el lenguaje no puede definir, el lenguaje sólo puede describir, dar cuenta de nuestra experiencia de los hechos. El lenguaje no altera la realidad, sólo se puede referir a ella:

Y mientras yo sondeaba aquella mina

de las lunas de la mitología

allí estaba, a la vuelta de la esquina,

la luna celestial de cada día. 
Hay una cierta circularidad en los sistemas semiológicos, y señaladamente en el lenguaje. Los signos que constituyen la lengua, si bien se refieren a hechos de nuestra experiencia del mundo, sólo adquieren su sentido al integrarse, de modo asaz autónomo, en el sistema mismo de la lengua. La expresión poética lo expresa con claridad pasmosa:
Sé que entre todas la palabras, una hay para recordarla o figurarla, el secreto, a mi ver, está en usarla con humildad, es la palabra luna.

El poeta ha entendido la lógica esencial del lenguaje. Se trata de un delicado y poderoso mecanismo de referencia a nuestra experiencia de la realidad que, articulada en palabras e inserto en una tradición, en una comunidad de interacción, nos permite, por su misma condición de patrimonio colectivo, entendernos a nosotros mismos y expresar nuestra especificidad:
Yo no me atrevo a macular su pura aparición con una imagen vana; la veo indescifrable y cotidiana y más allá de mi literatura.
Sé que la luna, o la palabra luna, es una letra que fue creada para la compleja escritura de esa rara cosa que somos, numerosa y una.

Finalmente, queda un misterio: de dónde procede este don o esta carga que lleva el ser humano. El poeta no tiene respuesta. El lingüista tampoco. La respuesta, si existe, habrá de buscarse en otras dimensiones. Por ahora, sólo queda jugarse a la esperanza:
Es uno de los símbolos que al hombre da el hado o el azar para que un día de exaltación gloriosa y de agonía pueda escribir su verdadero nombre.

6. En resumen, Jorge Luis Borges, en un poema, y ciertamente no el más elaborado de los suyos, ha calado en el fondo de la compleja red de interdependencias físicas, mentales, históricas y culturales que llamamos el lenguaje. Su intuición poética le ha permitido dar cuenta de este hecho con un nivel de precisión y lucidez que, una vez más, asombra al lingüista y lo obliga a replantearse la validez de sus métodos y la solidez de sus hallazgos. No es cosa 
de intentar profundas conclusiones ni de deprimirse; basta con una simple conclusión: el conocimiento que llamamos científico no es el único. La (buena) poesía es también, y entre otras cosas, conocimiento. Basta con que, como lingüistas lectores, agradezcamos al poeta su colaboración y continuemos en lo nuestro, claro que enriquecidos.

Nota final. Una versión inicial de este trabajo se leyó en el XI Congreso Internacional de Estudios Literarios de la Sociedad Chilena de Estudios Literarios, Pucón, noviembre de 2000.

\section{REFERENCIAS}

Barrenechea, Ana María. 1977. "Borges y los símbolos", en Revista Iberoamericana 100-101: 601-608.

Gallardo, Andrés. 1968. "Jorge Luis Borges, escritor sudamericano”, en Anales de la Facultad de Filosofía y Ciencias de la Educación (Pontificia Universidad Católica de Chile, Santiago): 240-251.

. 1991. "Lingüística en el poema", en Acta Literaria 16: 105-113.

Jakobson, Roman. 1960. "Linguistics and poetics", en Thomas A. Sebeok, Ed., Style in language, Cambridge, Massachusetts, The M.I.t. Press.

Muñoz Millanes, José. 1977. "Borges y la 'palabra' del universo", en Revista Iberoamericana 100-101: 615-625.

Rabanales, Ambrosio. 1979. "Las interdisciplinas lingüísticas", en Boletín de Filología XXX: 241-252.

Sarlo, Beatriz. 1995. Borges, un escritor en las orillas. Buenos Aires, Ariel.

Watkins, Culvert. 1976. "The Indo-European origin of English", en The American Heritage dictionary of the English language. Boston, etc., Houghton Mifflin Co., pp. XIX-XX. 


\section{APENDICE \\ Texto del poema "La luna”, de El Hacedor, 1960.}

(Este texto borgeano, al igual que todos los citados en el presente trabajo, se toma de Jorge Luis Borges: Obra poética 1923-1985. Buenos Aires, Emecé Editores, 1989 (20a).

\section{LA LUNA}

Cuenta la historia que en aquel pasado tiempo en que sucedieron tantas cosas reales, imaginarias y dudosas, un hombre concibió el desmesurado

proyecto de cifrar el universo en un libro y con ímpetu infinito erigió el alto y arduo manuscrito y limó y declamó el último verso.

Gracias iba a rendir a la fortuna cuando al alzar los ojos vio un bruñido disco en el aire y comprendió, aturdido, que se había olvidado de la luna.

La historia que he narrado aunque fingida, bien puede figurar el maleficio de cuantos ejercemos el oficio de cambiar en palabras nuestra vida.

Siempre se pierde lo esencial. Es una ley de toda palabra sobre el numen. No lo sabrá eludir este resumen de mi largo comercio con la luna.

No sé dónde la vi por vez primera, si en el cielo anterior de la doctrina del griego o en la tarde que declina sobre el patio del pozo y de la higuera.

Según se sabe, esta mudable vida puede, entre tantas cosas, ser muy bella 
y hubo así alguna tarde en que con ella te miramos, oh luna compartida.

Más que las lunas de las noches puedo recordar las del verso: la hechizada dragon moon que da horror a la balada y la luna sangrienta de Quevedo.

De otra luna de sangre y de escarlata habló Juan en su libro de feroces prodigios y de júbilos atroces; otras más claras lunas hay de plata.

Pitágoras con sangre (narra una tradición) escribía en un espejo y los hombres leían el reflejo en aquel otro espejo que es la luna.

De hierro hay una selva donde mora el alto lobo cuya extraña suerte es derribar la luna y darle muerte cuando enrojezca el mar la última aurora.

(Esto el norte profético lo sabe y también que ese día los abiertos mares del mundo infestará la nave que se hace con las uñas de los muertos.)

Cuando, en Ginebra o Zurich, la fortuna quiso que yo también fuera poeta, me impuse, como todos, la secreta obligación de definir la luna.

Con una suerte de estudiosa pena agotaba modestas variaciones, bajo el vivo temor de que Lugones ya hubiera usado el ámbar o la arena.

Pensaba que el poeta es aquel hombre que, como el rojo Adán del Paraíso, impone a cada cosa su preciso y verdadero y no sabido nombre. 
Ariosto me enseñó que en la dudosa luna moran los sueños, lo inasible, el tiempo que se pierde, lo posible o lo imposible, que es la misma cosa.

De la Diana triforme Apolodoro me dejó divisar la forma mágica; Hugo me dio una hoz que era de oro, y un irlandés, su negra luna trágica.

$\mathrm{Y}$, mientras yo sondeaba aquella mina de las lunas de la mitología, ahí estaba, a la vuelta de la esquina, la luna celestial de cada día.

Sé que entre todas las palabras, una hay para recordarla o figurarla. El secreto, a mi ver, está en usarla con humildad. Es la palabra luna.

Yo no me atrevo a macular su pura aparición con una imagen vana; la veo indescifrable y cotidiana y más allá de mi literatura.

Sé que la luna o la palabra luna es una letra que fue creada para la compleja escritura de esa rara cosa que somos, numerosa y una.

Es uno de los símbolos que al hombre da el hado o el azar para que un día de exaltación gloriosa o de agonía pueda escribir su verdadero nombre.

The heuristic potential of poetry is approached through a reading of Jorge Luis Borges' text "La luna" ["The moon"]. In this poem, Borges offers a very insightful, albeit implicit, view of language as a communicative and cultural system. 